\title{
The Loss of Bone Mineral with Aging and Its Relationship to Risk of Fracture
}

\author{
Davm M. Smith, M. R. A. Khairi, and C. Conrad Johnston, JR. \\ From the Department of Medicine, Indiana University School of Medicine, \\ Indianapolis, Indiana 46202
}

A B S T RACT Longitudinal studies have shown that individuals lose bone mineral at unequal rates with aging. It has been postulated that individuals with the more rapid rates of loss constitute a separate population having an increased risk for developing fractures, i.e., osteoporosis. To examine this postulate, we made a search for a separate population of elderly women using a precise and objective measurement technique of bone mineral, photon absorptiometry.

Bone mineral content (BMC) was measured in the radius of 571 Caucasian females who were age 50 or older. It was found that BMC values adjusted for width had a normal distribution in all decades and the variation in BMC values did not increase with age. Subjects with vertebral fractures $(n=108)$ were estimated to be losing bone mineral at the same rate as those without vertebral fractures $(n=161)$. Thus evidence for a separate population of rapid losers of bone mineral was not found.

Reconciliation of longitudinal studies which show unequal rates of loss with the present population survey, in which evidence for unequal rates was not found, would require that $(a)$ the rate of loss of bone mineral for an individual is not constant and/or $(b)$ the rate of mineral loss is proportional to the amount of mineral present at maturity.

The incidence of vertebral fractures was inversely proportional to BMC values. In a group of 278 women followed for 470 subject-yr, the incidence of all fractures during the study $(n=31)$ was also inversely proportional to $\mathrm{BMC}$. These data suggest that the $\mathrm{BMC}$ values of osteoporotics would be at the lower end of normally distributed values for the population.

\section{INTRODUCTION}

Many hypotheses have been proposed for the pathophysiological development of osteoporosis. One which

Received for publication 3 September 1974 and in revised form 14 April 1975. was reviewed by Newton-John and Morgan (1) postulates that there is a universal rate of loss of bone mineral with aging and those subjects with low bone mineral at maturity are the most susceptible to the development of osteoporosis. Doyle (2) has reviewed the evidence against this hypothesis and has suggested instead several models for development of the disease. Evidence is presented to support a hypothesis where a population of individuals exist who lose bone at a more rapid rate and may subsequently develop fractures.

The photon absorption technique for the measurement of bone mineral of the radius in vivo (3) is being utilized in a variety of clinical investigations (4-12). The purposes of this study were: $(a)$ to test these hypotheses with this technique and $(b)$ to determine the relationship between radial bone mineral measurements and the major clinical feature of osteoporosis, fractures.

\section{METHODS}

Bone mineral measurement. Bone mineral measurements were performed at midshaft and distal sites of the right radius with the Norland-Cameron Bone Mineral Analyzer as previously described $(10,13)$. The instrument is standardized to a known standard bone phantom before and after each subject is scanned. Four scans are done at each site and the mean of the four scans is used as the measurement of bone mineral content (BMC) ${ }^{1}$ (expressed in units of grams per centimeter) and of width (in centimeters) for that subject. The precision of this method has been determined on subjects of various ages to be 2.6 and $3.6 \%$ (coefficient of variation) for midshaft and distal mass and to be 1.7 and $3.8 \%$ for midshaft and distal width, respectively (13).

The source and selection of subjects. The sources of the 941 Caucasian female subjects and the mean age of each group are listed in Table I. All subjects had at least a brief

\footnotetext{
${ }^{1}$ There are differences of opinion as to whether this measurement should be called "bone mass" or "bone mineral content." The authors and others have used both terms. Since the units are grams per centimeter, we should prefer to call the measurement "bone mineral content" and reserve the term "mass" for measurements which are only in units of mass, i.e. grams.
} 


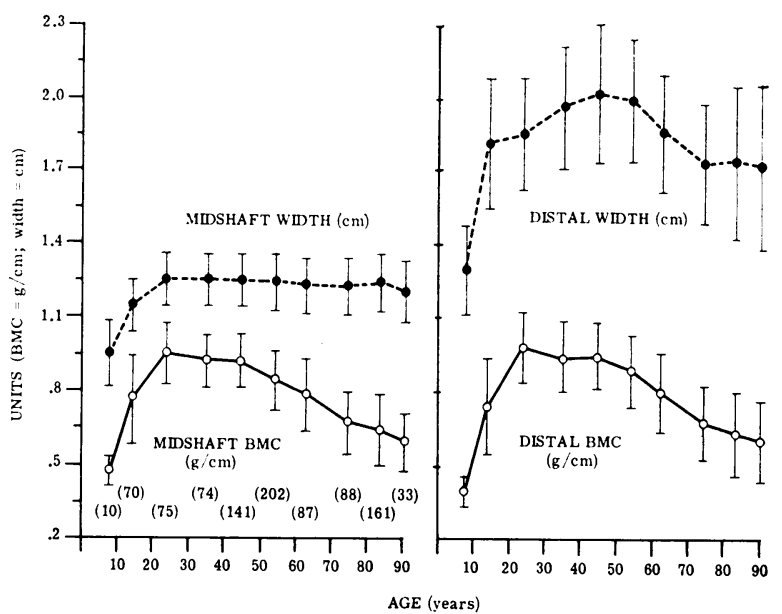

FIGURE 1 Photon absorption measurements of BMC and width of the right radius on 941 Caucasian females. The population was divided into decades, i.e. $0-9,10-19$, etc., and the mean values $\pm S D$ are plotted at the mean age of each group. The number of subjects in each group is shown in parentheses.

medical history. In addition, 459 subjects $(49.4 \%$ of the total population) over the age of 30 had a complete medical history, SMA-12, hemoglobin, WBC, and urinalysis as screening tests. These subjects included $269(29.2 \%$ of the total population) over the age of 50 who, in addition, had complete physical examinations and $\mathrm{X}$ rays of the chest and thoracic and lumbar spine.

Subjects with organic bone disease other than osteoporosis, chronic liver disease, renal disease, or evidence of malignancy or a disease known to affect bone metabolism were excluded. 54 subjects on estrogens or birth control pills were not excluded, but subjects on cortisone were excluded. Subjects with diseases such as osteoarthritis, heart disease, or diabetes mellitus with onset after age 50 were not excluded.

Methods of statistical analysis. Differences between group means were analyzed by Student's $t$ test (14). Polynominal regression analysis was performed by using Biomedical

TABLE I

Description of the Population of Caucasian Females Selected for Study

\begin{tabular}{lccc}
\hline \multicolumn{1}{c}{ Group } & $\begin{array}{c}\text { Age } \\
(\text { Mean } \pm \text { SD })\end{array}$ & $\begin{array}{c}\text { Absolute } \\
\text { frequency }\end{array}$ & $\begin{array}{c}\text { Relative } \\
\text { frequency }\end{array}$ \\
\hline $\begin{array}{l}y r \\
\text { Homes for the aged }\end{array}$ & $81 \pm 7.6$ & 286 & $\%$ \\
$\begin{array}{l}\text { Gynecology clinic } \\
\text { Medical center stu- } \\
\text { dents and employees }\end{array}$ & $50 \pm 10.5$ & 295 & 31.3 \\
$\begin{array}{c}\text { Juvenile twins and } \\
\text { their parents }\end{array}$ & $40 \pm 15.5$ & 151 & 16.1 \\
$\begin{array}{c}\text { Referred as } \\
\text { osteoporosis }\end{array}$ & $59 \pm 14.9$ & 143 & 15.2 \\
$\begin{array}{c}\text { Visitors } \\
\text { Total }\end{array}$ & $38 \pm 15.8$ & 14 & 1.5 \\
\hline
\end{tabular}

Computer Programs (15). Significance of regression coefficients was tested by $F$ ratios. Significant difference between regression coefficients was tested by Student's $t$ test (16). Weighted regression analysis was performed according to Anderson and Bancroft (17). The normality of distribution was tested by the chi-square goodness of fit test (18). The test for linear trend in proportions and the Bartlett's test for homogeneity were performed according to Snedecor and Cochran (18).

Methods for normalization of data. The two variables, bone width and age, have been shown to have significant effects on bone mineral values $(4,13,19)$. To determine how these variables affect conclusions derived from bone mineral values, the data were analyzed with and without normalization procedures. Midshaft width was selected as the basis for normalization of BMC at both sites since $(a)$ it is a more precise measurement, C.V. $=1.7 \%$ for midshaft radius vs. $3.8 \%$ for distal radius $(13) ;(b)$ it does not vary with age (Fig. 1), whereas distal width does (5); and (c) the regression coefficient of distal BMC vs. distal width was not significantly different from zero, whereas the regression coefficient was significant between distal BMC and midshaft width in all 10 -yr age groups below age 50 . The method for normalization for width was chosen with the objective of removing the size variable without changing the effect of age on BMC. Since age has no effect on BMC from age 30 to 49 (Fig. 1), the relationship between $\mathrm{BMC}$ and width was determined by regression analysis for the 215 subjects in this age group. The linear regression equations determined were :

midshaft $\mathrm{BMC}=(0.712) \quad$ (midshaft width) +0.03 , and distal $\mathrm{BMC}=(0.486)$ (midshaft width) +0.34 .

For this group the midshaft BMC could be adjusted by dividing by width or by a regression equation. However, distal BMC is best adjusted by regression because of the relatively large intercept of 0.34 . After age $50, \mathrm{BMC}$ decreases but width remains constant; thus, the mass-to-width relationship changes with aging. For this older group, the effect of width on BMC can be removed by using regression equations without changing the age effect. Thus, the normalization was done by regression equations for all age groups. The equation used to adjust BMC to the mean midshaft width for all subjects over age 30 were:

midshaft $\mathrm{BMC}$ adjusted to width $1.25 \mathrm{~cm}=$ midshaft $\mathrm{BMC}$

$+0.712(1.25$ - midshaft width $)$, and

distal BMC adjusted to width $1.25 \mathrm{~cm}=$ distal $\mathrm{BMC}$ +0.486 (1.25 - midshaft width).

After adjusting for width, regression analysis of BMC adjusted for width vs. age on subjects over age 50 was performed:

midshaft $\mathrm{BMC}$ adjusted to width $1.25 \mathrm{~cm}=-0.0250$

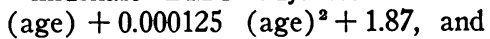

distal $\mathrm{BMC}$ adjusted to width $1.25 \mathrm{~cm}=-0.0285$ (age)

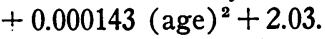

There was a significant quadratic term, which is reflected in the equations for normalizing the mass to a mean age of 70 :

midshaft BMC adjusted to age 70 and width $1.25 \mathrm{~cm}=$ midshaft BMC adjusted to width $1.25 \mathrm{~cm}+(0.025)$ (age) $-(0.000125)(\text { age })^{2}-1.14$, and

distal BMC adjusted to age 70 and width $1.25 \mathrm{~cm}=$ distal BMC adjusted to width $1.25 \mathrm{~cm}+(0.0285)$ (age) + $(0.000143)$ (age) $)^{2}-1.29$

\section{RESULTS}

Age-related loss of bone mass. If $\mathrm{BMC}$ is normally distributed at maturity, and if all women lose bone min- 
eral at an equal rate, then the $\mathrm{BMC}$ values should have a normal distribution throughout all ages. Should there be a group of rapid losers who develop fractures, bimodality may be found in the population. This is especially true in the older age group where the incidence of vertebral fractures approaches $50 \%$.

In order to test the BMC data for a normal distribution, one should either have a large population of the same age and bone width or remove the effect of these variables by normalization. In this study we have removed the variable effects by normalization.

Fig. 2 illustrates the frequency distribution of midshaft BMC values after age 50 before and after adjusting for width and age. After adjusting for width alone (middle panel), the distribution of midshaft $\mathrm{BMC}$ appears to be bimodal, reflecting the bimodal distribution of age sampling (Fig. 1 bottom). After adjusting for width and age, the frequency distribution appears as a bell-shaped curve. The chi-square test for "goodness of fit" to a normal distribution (18) shows
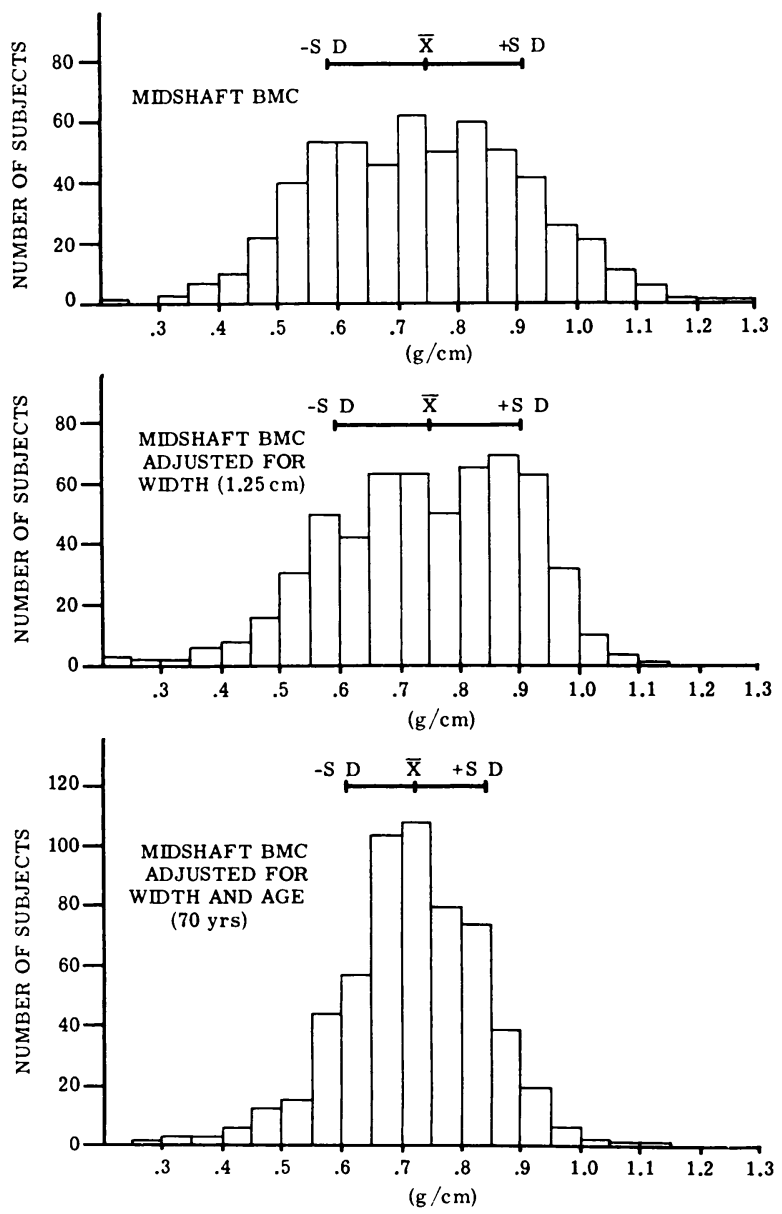

FIGURE 2 Frequency distribution of BMC measurements of the midshaft radius on 571 women age 50 and older.

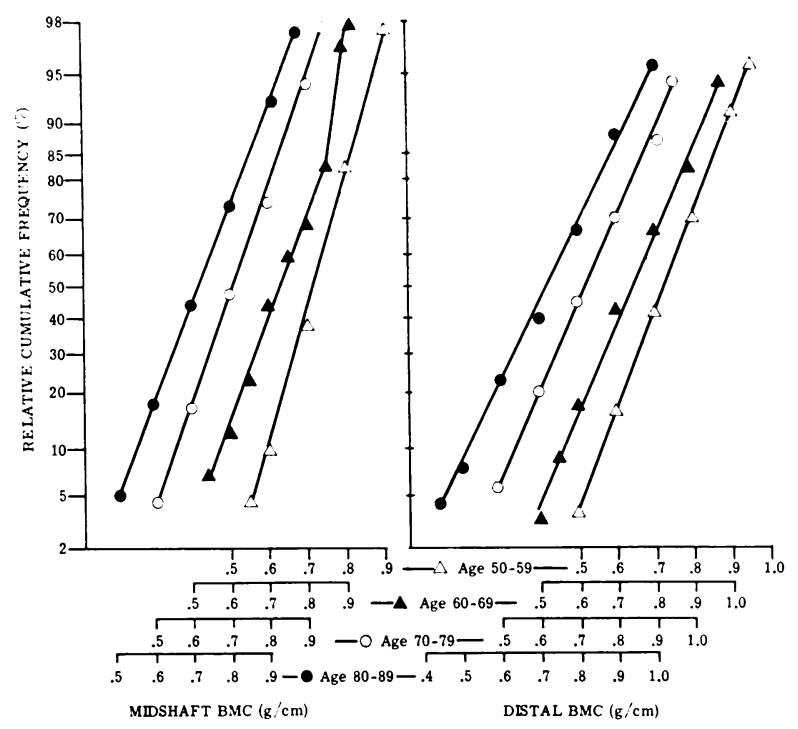

FIgure 3 Probit curves plotted for midshaft BMC and distal BMC after adjusting for width and age. The scale for BMC units is staggered in order to separate the curves and allow comparisons.

no significant difference (chi-square $=9.214$ with $\mathrm{df}=$ 5 ) between the observed values and the predicted normal frequency distribution for midshaft BMC after adjusting for width and age. Similar results were found for distal BMC (chi-square=4.104 with $\mathrm{df}=5$ ). Thus, after pooling all observations on subjects over the age of 50 the hypothesis of normality could not be rejected.

Normality may also be tested by probit analysis where the relative cumulative frequency of observations plotted against the observed value forms a straight line when the observations have a normal distribution. This analysis of BMC adjusted for width and age is shown in Fig. 3. Here the group, age $90-99$, was omitted because of the small sample size of 33 . With the single exception of midshaft BMC in the age 60-69 group, the plots are linear, indicating a normal distribution for all age groups. Although the finding may indicate a subpopulation in one decade at one site, it is more likely an indication of sampling error since this is one of the smaller groups. In addition, probit analysis was performed with BMC values adjusted for age only (not width) and again the plots were linear, indicating a normal distribution. Thus, there is very little evidence for bimodality (two separate populations) in these age groupings.

Bimodality might not be seen if the population of rapid losers was relatively small. In this case, one might find an increase in variance of $\mathrm{BMC}$ with aging. The effect of age on variance, which is $\mathrm{SD}^{2}$, was examined by testing the significance of the regression coeffi- 
TABLE II

Comparison of BMC Measurements on 161 Women without Vertebral Fracture to 108 Women with Vertebral Fracture

\begin{tabular}{|c|c|c|c|c|c|}
\hline Group & $\begin{array}{l}\text { Measurement } \\
(\text { Mean } \pm \mathrm{SD})\end{array}$ & $P$ & $\begin{array}{l}\text { Regression coefficient } \\
\quad \text { (vs. age } \pm \mathrm{SE})\end{array}$ & $t$ & $P$ \\
\hline & $\mathrm{g} / \mathrm{cm}$ & & & & \\
\hline \multicolumn{6}{|l|}{ Midshaft mass } \\
\hline Nonfracture & $0.74 \pm 0.16$ & & $0.00656 \pm 0.00076$ & & \\
\hline Fracture & $0.65 \pm 0.14$ & $<0.001$ & $0.00754 \pm 0.00113$ & 0.695 & NS \\
\hline \multicolumn{6}{|l|}{ Distal mass } \\
\hline Nonfracture & $0.75 \pm 0.18$ & & $0.00755 \pm 0.00093$ & & \\
\hline Fracture & $0.64 \pm 0.17$ & $<0.001$ & $0.00975 \pm 0.00131$ & 1.321 & NS \\
\hline \multicolumn{6}{|c|}{ Midshaft mass adjusted for width $(1.25 \mathrm{~cm})$} \\
\hline Nonfracture & $0.76 \pm 0.11$ & & $0.00616 \pm 0.00063$ & & \\
\hline Fracture & $0.71 \pm 0.12$ & $<0.001$ & $0.00662 \pm 0.00113$ & 0.178 & NS \\
\hline \multicolumn{6}{|c|}{ Distal mass adjusted for width $(1.25 \mathrm{~cm})$} \\
\hline Nonfracture & $0.77 \pm 0.17$ & & $0.00725 \pm 0.00084$ & & \\
\hline Fracture & $0.65 \pm 0.17$ & $<0.001$ & $0.00909 \pm 0.00135$ & 1.158 & NS \\
\hline
\end{tabular}

cients of variance of unadjusted midshaft BMC, distal $\mathrm{BMC}$, and midshaft width vs. age. Since the number of subjects in each age group was different, it was necessary to use a weighted regression analysis (17) to test if the variance changed significantly with age. These calculations showed no change in variance of midshaft BMC $(\mathrm{b}=0.00012+0.00076, P>0.10)$ or distal BMC $(\mathrm{b}=0.00018+0.00091, P>0.05)$ with age. However, the variance of midshaft width did increase significantly with age $(b=0.00007+0.00002, \quad P<$ $0.05)$. In addition, the more sensitive Bartlett test for homogeneity of variances was performed (18) and significant inequality of variances of BMC for different age groups could not be demonstrated.

Thus, the variance of both midshaft and distal BMC did not increase significantly with age. It might be argued that the regression coefficient of the variance of distal BMC vs. age approached significance $(P<0.10$, $>0.05)$. However, the measurement of distal BMC is less precise in older subjects (13) and may account for some increased variance with age. The absence of a significant increase in the variance of midshaft and distal BMC with age is further evidence against a subpopulation of rapid losers of bone mineral.

Relationship of BMC measurements to vertebral fractures. For this study all Caucasian women age 50 or older who had spinal $\mathrm{X}$ rays were included $(n=$ 269). A vertebral body was classified as fractured (collapsed) if it was decreased at least one-third in height. The women were divided into nonfracture $(n=$ $161)$ and fracture $(n=108)$ groups on the basis of absence or presence of a vertebral fracture. The mean age of the nonfracture group was 73 and the mean age of the fracture group was 78 . Only 21 of the 108 fractures were in subjects under the age of 70 . The results in Table II demonstrate $(a)$ that the nonfracture group has a significantly higher $(P<0.001) \mathrm{BMC}$ before and after adjusting for width and $(b)$ that the linear regression coefficients of BMC vs. age (rate of loss) are not significantly different between nonfracture and fracture groups. These results are similar to those reported previously (19) for a smaller group $(n=169)$. In addition, the regression coefficients of midshaft $\mathrm{BMC}$ vs. age and distal $\mathrm{BMC}$ vs. age within each group were not significantly different from each other $(P>0.40$ and $P>0.10)$, indicating a uniform rate of loss at the two sites.

If one assumes that the population had been randomly subjected to mild trauma, then the hypothesis that the incidence of fracture should increase in groups with lower BMC can be examined. The population was divided into arbitrary levels of $\mathrm{BMC}$ values and the incidence of fracture at each level was computed. The results in Table III demonstrate an inverse relationship of BMC values with incidence of fracture. At both sites and both before and after adjustment for width, the slope of fracture incidence vs. level of BMC was significantly $(P<0.001)$ different from zero and the hypothesis for linear trend in proportions could not be rejected (18). The overall chi-square was also significant $(P<0.001)$, indicating that there were highly significant differences among the BMC-specific proportions. This inverse linear relationship would allow the identification of groups of individuals with 2 or 3 times the incidence of fracture over other groups on the basis of low bone mineral values. 
TABLE III

Relationship of BMC Measurements to Incidence of Vertebral Fractures

\begin{tabular}{|c|c|c|c|c|c|}
\hline & \multicolumn{5}{|c|}{ Measurement } \\
\hline & $\geq 0.90^{*}$ & $0.89-0.80$ & $\begin{array}{c}\mathrm{g} / \mathrm{cm} \\
0.79-0.70\end{array}$ & $0.69-0.60$ & $\leq 0.59$ \\
\hline \multicolumn{6}{|l|}{ Midshaft mass } \\
\hline Total & 29 & 45 & 60 & 65 & 70 \\
\hline Number with fracture & 5 & 15 & 17 & 30 & 41 \\
\hline Percent with fracture & $17 \%$ & $33 \%$ & $28 \%$ & $46 \%$ & $59 \%$ \\
\hline \multicolumn{6}{|c|}{ Midshaft mass adjusted to width $(1.25 \mathrm{~cm})$} \\
\hline Total & 32 & 48 & 75 & 63 & 51 \\
\hline Number with fracture & 7 & 10 & 28 & 28 & 35 \\
\hline Percent with fracture & $22 \%$ & $21 \%$ & $37 \%$ & $44 \%$ & $69 \%$ \\
\hline \multicolumn{6}{|l|}{ Distal mass } \\
\hline Total & 39 & 44 & 60 & 50 & 76 \\
\hline Number with fracture & 7 & 12 & 24 & 18 & 47 \\
\hline Percent with fracture & $18 \%$ & $27 \%$ & $40 \%$ & $36 \%$ & $62 \%$ \\
\hline \multicolumn{6}{|c|}{ Distal mass adjusted to width $(1.25 \mathrm{~cm})$} \\
\hline Total & 38 & 48 & 65 & 53 & 65 \\
\hline Number with fracture & 9 & 10 & 28 & 20 & 41 \\
\hline Percent with fracture & $24 \%$ & $21 \%$ & $43 \%$ & $38 \%$ & $63 \%$ \\
\hline
\end{tabular}

* The ranges of values were chosen arbitrarily.

It has been reported that patients with osteoporosis are shorter and lighter than controls (20), which might indicate difference in skeletal size. The mean midshaft width for the nonfracture group $(1.22 \pm 0.12 \mathrm{~cm})$ was not significantly different $(P>0.18)$ from the fracture group $(1.22 \pm 0.12 \mathrm{~cm})$, suggesting that skeletal size was not different in the two groups.

The relationship of $B M C$ measurements to subsequent fractures. Subjects were selected out of this Caucasian female population who $(a)$ were age 50 or older, (b) had bone mineral measurements of the right arm, (c) had no evidence of organic disease by medical history or laboratory screen, and $(d)$ had been followed with visits every 1-3 mo. The mean age of the 278 women selected was $66 \pm 14$ (SD) yr with a range of $50-96.50 \%$ of the population was below age 60 . They were followed for a mean period of $1.7 \mathrm{yr}$ with a range of $6 \mathrm{wk}-3.4 \mathrm{yr}$. The total follow-up period was 470 subject-yr. Any significant and/or persistently painful area were X-rayed for fracture. During this period, fractures occurred in 31 subjects (16 of these were age 65 or less) for an incidence of 6.6 fractures per 100 subject-yr. The site of fracture varied widely throughout all ages, except that "march" fractures of the metatarsals were the most frequent under the age of 65 . None of the fractures resulted from severe trauma such as an auto accident, and most resulted from falls at ground level.

The initial BMC measurements and their relationship to subsequent fracture is shown in Table IV. Although the total number of subjects and fractures are few, the BMC measurements reflect an inverse relationship to fracture incidence similar to that of vertebral fractures. Here the slope of fracture incidence vs. level of BMC was significant $(P<0.05)$ at both sites before and after adjusting for width, and the hypothesis for linear trend in proportions could not be rejected. However, the overall chi-square was only significant $(P<$ 0.05) for distal BMC after adjusting for width (18), which may occur when the total incidence of fracture is small.

\section{DISCUSSION}

This study has utilized bone mineral measurements of the radius in an investigation of the generalized skeletal loss of mineral with aging and/or osteoporosis. This approach is reasonable because it has been shown that (a) both distal and midshaft bone mineral measurements correlate well ( $r=0.94$ and 0.84 , respectively) with total body calcium determined by neutron activation (21), (b) both distal and midshaft bone mineral measurements of cadavers correlate $(r=0.84$ and 0.86$)$ with photon absorption measurements of mineral of the neck of the femur (22), and (c) both distal and midshaft bone mineral measurements of cadavers correlate $(r=0.60$ and $r=0.70$ ) with photon absorption measurements of mineral of thoracic vertebra (22). In addition, although osteoporosis more commonly involves the axial skeleton, fractures of the distal radius are 
TABLE IV

Relationship of BMC Measurements to Incidence of Subsequent Fractures

\begin{tabular}{lccccc}
\hline & \multicolumn{5}{c}{ Measurement } \\
\cline { 2 - 6 } & $\geq 0.90 *$ & $0.89-0.80$ & $0.79-0.70$ & $0.69-0.60$ & $\leq 0.59$ \\
\hline Midshaft mass & & & & \\
$\quad$ Total & 60 & 68 & 61 & 47 & 42 \\
Number with fractures & 5 & 5 & 5 & 8 & 8 \\
Percent with fractures & $8 \%$ & $7 \%$ & $8 \%$ & $17 \%$ & $19 \%$ \\
Midshaft mass adjusted to width & $(1.25 \mathrm{~cm})$ & & & & \\
Total & 74 & 78 & 53 & 43 & 30 \\
Number with fractures & 5 & 7 & 6 & 6 & 7 \\
Percent with fractures & $7 \%$ & $9 \%$ & $11 \%$ & $14 \%$ & $23 \%$ \\
Distal mass & & & & & \\
Total & 72 & 51 & 60 & 49 & 46 \\
Number with fractures & 5 & 4 & 8 & 4 & 10 \\
Percent with fractures & $7 \%$ & $8 \%$ & $13 \%$ & $8 \%$ & $22 \%$ \\
Distal mass adjusted to width & $(1.25 \mathrm{~cm})$ & & & & \\
Total & 68 & 68 & 52 & 49 & 41 \\
Number with fractures & 2 & 9 & 5 & 6 & 9 \\
Percent with fractures & $3 \%$ & $13 \%$ & $10 \%$ & $12 \%$ & $22 \%$ \\
\hline
\end{tabular}

* The ranges of values were chosen arbitrarily.

quite common in this disease (1). Thus, it seems justified at the present time to use changes at these scan sites as a reflection of generalized mineral loss from the skeleton with aging.

There is little evidence in our data to support the existence of a subpopulation of rapid losers of bone mineral. The data are consistent with hypothesis of a normal distribution of bone mineral values since there was no evidence of bimodality (Fig. 2). The distribution of values in each 10-yr age group, with only a single exception, was also normal (Fig. 3). The failure to find evidence for bimodality in the distribution of bone mineral values does not prove that a subpopulation does not exist (23). However, the population studied is relatively large and the incidence of disease (fractures) in this group is also considerable. Further evidence against the existence of a subpopulation was the finding that the variation of BMC did not increase significantly with age. Finally, there is no significant difference in the estimated rates of loss (Table II) between women with and without vertebral fractures. Thus, these data support the thesis previously presented by this laboratory (4) and by Newton-John and Morgan in their analysis of the literature (1) that there is a general rate of loss for the population and that the persons with a low bone mineral at maturity are most susceptible to osteoporosis.

The evidence for the alternative hypothesis, that osteoporotics are subjects with a more rapid rate of mineral loss, has been reviewed by Doyle (2). Much of the data in support of this hypothesis comes from prospective or longitudinal studies of the measurement of rates of loss. Longitudinal studies by Garn, Rohmann and Wagner (24), Adams, Davies, and Sweetnam (25), and Dequeker (26) have demonstrated unequal rates of loss among individuals. Our laboratory, using the photon absorption technique (27), also found that the rate of loss varied significantly in a population of 24 postmenopausal females followed for $2.4 \mathrm{yr}$. Thus it would appear that individuals do lose bone mineral at different rates. At least two models would explain these apparently discrepant results and they are shown in Fig. 4. In the first model the rate of loss of mineral is not constant with time. Thus a rapid loser for a 2-yr period may become a slow loser over the next 2 yr (Fig. 4c). The other model (Fig. 4d) proposes that the rates of loss are directly related to the amount of mineral present at maturity. Thus, subjects with high mineral content would lose at rates equal to the average or faster; and subjects with low mineral content would lose at rates equal to the average or slower. Thus, there could be unequal rates among individuals yet there would be no increased variance in the population with aging.

Doyle (2) has discussed the models shown in Fig. $4 a$ and $4 b$ and in addition two other models in which the amount of mineral loss was related to the amount of bone at age 45 . In one model the amount of bone loss is directly proportional to the mineral at maturity. This condition would decrease the variance of $\mathrm{BMC}$ with 
aging. In the other model the amount of bone loss is inversely proportional to the mineral at maturity. This condition would increase the variance of $B M C$ with aging. The data presented in our study failed to demonstrate any change in variance of BMC with aging. Although Dequeker (26) found varying losses of cortical thickness in a longitudinal study (only $63 \%$ of the females had a decrease), his population survey, when divided into groups of varying skeletal sizes, indicated a parallel loss of cortical area for each size. Our studies confirm Dequeker's findings in that individuals are found to be losing at different rates and yet the variance of the population does not increase with aging. The models in Fig. $4 c$ and $d$ would best explain these results.

The photon absorption technique is capable of determining which of the proposed models is appropriate for osteoporosis. However, it would appear that a large number of subjects followed for a long period of time will be required to adequately answer the question.

The value of bone mineral measurements in the prediction of risk of fracture appears promising. However, it is evident that factors other than low bone mineral

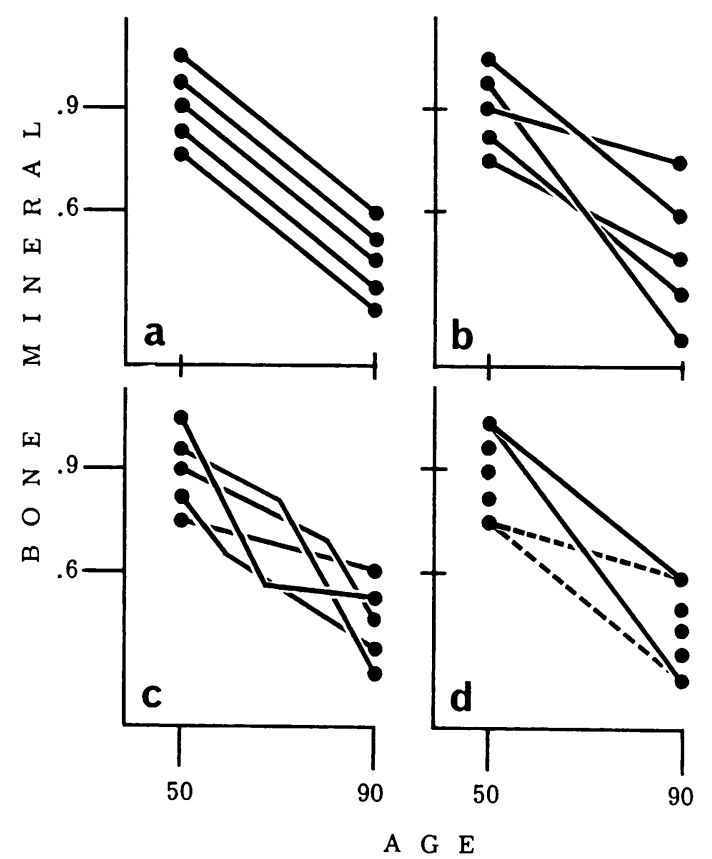

FIGURE 4 Models for the development of osteoporosis. The theoretical effect of aging on bone mineral in five individuals with varying amounts of bone mineral at age 50. (a) A universal rate of loss unrelated to the amount of mineral at maturity. (b) Varying rates of loss unrelated to the amount of mineral at maturity. (c) Rates of loss not constant with time. (d) Varying rates of loss generally related to initial bone mineral. may be determinants of fracture, as well. These factors may include degree of trauma, quality of bone, activity, or other unknowns. Thus an individual subject with low bone mineral has only one of the factors which increases his risk of fracture.

It is interesting to compare our results with those of Iskrant and Smith (28), who followed 2,100 women age 45 and older for $3 \mathrm{yr}$. Their reported fracture rate was 2.0 per 100 subject-yr in nonosteoporotics (from $\mathrm{X}$ rays of lumbar spine) and 7.0 per 100 subject-yr in osteoporotics. The higher rates of fracture found in the present study may have occurred because of the higher proportion of older subjects and the increased frequency of radiologic examinations performed. Whether or not the radiographic examination of the lumbar spine serves as a better predictor of subsequent fracture than the photon absorption technique will require a comparative study. However, the photon absorption technique has been shown to be significantly more precise than visual scoring of radiographs (29).

There are reports that the photon absorption method was diagnostic of spinal osteoporosis (30) and not useful in the early detection of osteoporosis (5). It is difficult to agree with either conclusion. The value of the photon absorption technique in the diagnosis of osteoporosis depends upon the definition of the disease. A generally accepted definition of osteoporosis would be a loss of bone mineral with fracture for which no other cause is found. If a fracture is a necessary part of the definition, then photon absorption will never equal the radiographic examination. It is apparent that $\mathrm{BMC}$ is a continuous variable and that the lower the value the greater the risk of developing fracture (Tables III and IV). If osteoporosis is defined as a significant loss of bone mineral ultimately leading to structural failure, then photon absorption measurements may be applicable to the detection of early osteoporosis (prefracture).

\section{ACKNOWLEDGMENTS}

The authors acknowledge the statistical assistance of $\mathrm{Dr}$. $\mathrm{J}$. Norton of the Section of Biostatistics, Department of Psychiatry, and S. Michael of Procter and Gamble Co.; the excellent technical assistance of P. Ogle, C. Shields, J. Davis, R. McVicar, L. Quick, and B. Harris; and the critical review by Dr. T-K. Li.

This investigation was supported in part by U. S. Public Health Service grant no. AM-07126 and by a grant from the Indianapolis Valley Ancient and Accepted Order of the Scottish Rite. The facilities of the Research Computer Center of Indiana University-Purdue University at Indianapolis (I.U.P.U.I.) were used for much of the statistical analyses.

\section{REFERENCES}

1. Newton-John, H. F., and D. B. Morgan. 1970. The loss of bone with age, osteoporosis and fractures. Clin. Orthop. Relat. Res. 71 : 229-252. 
2. Doyle, F. 1972. Involutional Osteoporosis. Clin. Endocrinol. Metab. 1 : 143-167.

3. Cameron, J. R., and J. Sorensen. 1963. Measurement of bone mineral in vivo: an improved method. Science (Wash. D. C.). 142: 230-232.

4. Johnston, C. C., Jr., D. M. Smith, P-L. Yu, and W. P. Deiss, Jr. 1968. In vivo measurement of bone mass in the radius. Metab. Clin. Exp. 17: 1140-1153.

5. Goldsmith, N. F., J. O. Johnston, G. Picetti, and C. Garcia. 1973. Bone mineral in the radius and vertebral osteoporosis in an insured population. J. Bone Jt. Surg. Am. Vol. 55A : 1276-1293.

6. Davis, M. E., N. M. Strandjord, and L. H. Lanzl. 1966. Estrogens and the aging process. JAMA (J.Am. Med. Assoc.). 196: 219-224.

7. Lockwood, D. R., J. E. Lammert, J. M. Vogel, and S. B. Hulley. 1973. Bone mineral loss during prolonged bedrest. In Clinical Aspects of Metabolic Bone Disease. B. Frame, A. M. Parfitt, and H. Duncan, editors. Excerpta Med. Int. Congr. Ser. No. 270. 261-265.

8. Griffiths, H. J., R. E. Zimmerman, G. Bailey, and R. Snider. 1973. The use of photon absorptiometry in the diagnosis of renal osteodystrophy. Radiology. 109: 277281.

9. Smith, E. L., Jr. 1971. Bone changes with age and physical activity. Doctoral thesis. University of Wisconsin, Madison, Wis. 109 pp.

10. Smith, D. M., W. E. Nance, K. W. Kang, J. C. Christian, and C. C. Johnston, Jr. 1973. Genetic factors in determining bone mass. J. Clin. Invest. 52: 2800-2808.

11. Mazess, R. B., and J. R. Cameron. 1972. Growth of bone in school children: comparison of radiographic morphometry and photon absorptiometry. Growth. 36: 77-92.

12. Cameron, J. R. 1969. Bone mineral normative data. Atomic Energy Commission, Progress Report. COO1422-41. University of Wisconsin, Madison, Wis.

13. Johnston, C. C., Jr., D. M. Smith, W. E. Nance, and J. Bevan. 1973. Evaluation of radial bone mass by the photon absorption technique. In Clinical Aspects of Metabolic Bone Disease. B. Frame, A. M. Parfitt, and H. Duncan, editors. Excerpta Med. Int. Congr. Ser. No. 270. 28-36.

14. Nie, N. H., D. H. Bent, and C. H. Hull. 1970. Statistical Package for the Social Sciences (SPSS). McGraw-Hill Book Co., New York. Update version 5.5

15. Biomedical Computer Programs. 1972. Indiana University-Purdue University at Indianapolis (I.U.P.U.I.) versions p. 222. From BMC Manual. 1964. W. S. Dixon, editor. University of California Press, Los Angeles, Calif.

16. Steel, R. G. D., and J. H. Torrie. 1960. Principles and Procedures of Statistics. McGraw-Hill Book Co., New York. $481 \mathrm{pp}$.
17. Anderson, R. L., and T. A. Bancroft. 1952. Statistical Theory in Research. McGraw-Hill Book Co., New York. 399 pp.

18. Snedecor, G. W., and W. G. Cochran. 1967. Statistical Methods. The Iowa State University Press, Ames, Iowa. 6th edition. $593 \mathrm{pp}$.

19. Smith, D. M., C. C. Johnston, Jr., and P-L. Yu. 1972. In vivo measurement of bone mass. JAMA (J. Am. Med. Assoc.). 219: 325-329.

20. Saville, P. D. 1970. Observations on 80 women with osteoporotic spine fractures. In Osteoporosis. U. S. Barzel, editor. Grune \& Stratton, Inc., New York. 38-46.

21. Chestnut, C. H., III, E. Manske, D. Baylink, and W. B. Nelp. 1973. Preliminary report-correlation of total body calcium (bone mass), as determined by neutron activation with regional bone mass as determined by photon absorption. In International Conference on Bone Mineral Measurement. Department of Health, Education, and Welfare. Publication No. (NIH) 75-683. 34-38.

22. Wilson, C. R. 1973. Prediction of femoral neck and spine bone mineral content from the $B M C$ of the radius or ulna and the relationship between bone strength and BMC. Department of Health, Education, and Welfare Publication No. (NIH) 75-683. 51-59.

23. Murphy, E. A. 1964. One cause? Many causes? The argument from the bimodal distribution. J. Chron. Dis. 17: 301-324.

24. Garn, S. M., C. G. Rohmann, and B. Wagner. 1967. Bone loss as a general phenomenon in man. Fed. Proc. 26: 1729-1736.

25. Adams, P., G. T. Davies, and P. Sweetnam. 1970. Osteoporosis and the effects of aging on bone mass in elderly men and women. Q. J. Med. 39: 601-615.

26. Dequeker, J. 1972. Bone Loss in Normal and Pathological Conditions. Leuven University Press, Antwerp, Belgium. 214 pp.

27. Smith, D. M., M. R. A. Khairi, and C. C. Johnston, Jr. 1973. Mineral loss with aging measured prospectively by the photon absorption technique. In International Conference on Bone Mineral Measurement. Department of Health, Education, and Welfare Publication No. (NIH) 75-683. 268-276.

28. Iskrant, A. P., and R. W. Smith. 1969. Osteoporosis in women 45 years and over related to subsequent fracture. Public Health Rep. 84: 33-38.

29. Colbert, C., R. B. Mazess, and P. B. Schmidt. 1970 Bone mineral determination in vitro by radiographic photodensitometry and direct photon absorptiometry. Invest. Radiol. 5 : 336-340.

30. Goldsmith, N. F., J. O. Johnston, H. Ury, G. Vose, and C. Colbert. 1971. Bone-mineral estimation in normal and osteoporotic women. J. Bone Jt. Surg. Am. Vol. 53A : $83-100$ 